University of Louisville

ThinkIR: The University of Louisville's Institutional Repository

\title{
A proposed study of the affect of group counseling upon students on academic probation at the University of Louisville.
}

\author{
Morrison L. Cooke \\ University of Louisville
}

Follow this and additional works at: https://ir.library.louisville.edu/etd

Part of the Counseling Psychology Commons, Higher Education Commons, and the Student Counseling and Personnel Services Commons

\section{Recommended Citation}

Cooke, Morrison L., "A proposed study of the affect of group counseling upon students on academic probation at the University of Louisville." (1949). Electronic Theses and Dissertations. Paper 2558.

https://doi.org/10.18297/etd/2558

This Master's Thesis is brought to you for free and open access by ThinkIR: The University of Louisville's Institutional Repository. It has been accepted for inclusion in Electronic Theses and Dissertations by an authorized administrator of ThinkIR: The University of Louisville's Institutional Repository. This title appears here courtesy of the author, who has retained all other copyrights. For more information, please contact thinkir@louisville.edu. 


\section{UNIVERSITY OF LOUISVILLE}

A Proposed Study of the Affect of Group "1 Counseling upon Students on Academic Probation at the University of Louisville

A Dissertation

Submitted to the Faculty

of the Graduate School of the University of Louisville

In Partial Fulfillment of the

Requirements for the Degree

of Waster of Arts

Departmel t of Psychology

By

Morrison L. Cooke

1949 
NAME OF STUDENT:

Morrison I. Cooke

TITLE OF THESIS: A Proposed Study of the Affect of Group Counseling upon Students on Academic Probation at the University of Louisville, Kentucky

APPROVED BY READING COMITTEE COMPOSED OF THE FOLLOWING NEMBERS:

Howell V. Williams

Noble H. Kelley

NAME OF DIRECTOR:

Clyde W. Smith

DATE:

June 3, 1949 
CONTENTS

Page

I. Introduction and Purpose of the Stuay 5

II. Review of the Literature 9

III. Statement of the Problem. Methods and Procedures

IV. Comrients

29

V. Sumnary

32

VI. Bibliography

35 


\section{Introduction and Purpose of the Study}

Psychotherapy is a term that has come to be given to many varied situations involving a relationship between one or more persons. In fact, it has been applied to such extreme conditions as an autobiography, in which an individual writes out his personal problems, and to a vast radio audience, in which one or more persons is thought capable of therapeutac action on the masses.

This vague use of the term has made it very difilcult to make any kind of scientific approach to the study of psychotherapy. There are almost as many definitions of the word as there are persons who use it. Iikewise, this has contributed to the many obstacles that arise in the evaluation or reasurement of psychotherapy. Nevertheless, the time has come to try to overcome some of these obstacles wherever possible. Therapists, as well as others, are crying for research in the field. But, while it is impossible to uncover any really valid results, or derive any reliable conclusions without some comparable measure of criteria, it would seem that such measures can only be discovered through research, and research methods.

It is not our position, nor our purpose, to attempt to produce a noncontradictory result, nor an infallible criterion of measurement. In any research 
where a limited population is used, when it is also a pioneer attempt, only an exploratory study can be made. With the extremely limited experience and knowledge of the field that we possess, we can do no more than scratch the surface of a problem which might be expanded to cover much of what has been written, and little of what is knom. However, somewhere there must be a begining, and if we are able to show only that this study may have merit in its theory, and perhaps indicate that more research might be worthwhile in this area, then we may feel that our efforts, at least, have not been in vain.

Were this a completed experiment, there would still be rauch to be desired before any sort of conclusions or predictions could be made, due to the narrow scope of the material. At best, we could only imply, or infer, or suggest the possibility of for future trials, even though our results were everything we hoped they would be. Therefore, let us hope that this study will give encouragement to other Neophytes who, in the everlasting search for the Truth, like us, wlll "rush in where angels fear to tread."

The purpose of this exploratory study is to determine experimentally whether students on Academic Probation in the College of Arts and Sciences of the University of Louisville may be enabled to increase their quality-polint stanaing after group counseling at the Psychological Services Center of the University. The center has recently begun to offer its counseling services 
to students of the University, and particularly to those on Probation in the Colilege of Arts and Sciences. In order to determine to some extent the effectiveness of the program, from the standpoint of the College and the Center both, some measure of evaluation must be utilized. Inasmuch as the quality-point standing of students in the College is the determinant by which they may be placed on Probation, and likewise be removed from Probation, thus being a measure of achievement according to the College's own standards, it is logical to use this standing experimentally as an evaluative measure. We hope, accordingly, to be able to observe winether group counseling, in a given situation, will be effective in one area, at least. Our hypothesis is derived from this theory, namely: That group counseling of students on Acaderic Probation in the College of Arts and Sciences of the University of Iouisville, through the medium of the Psychological Services Center of the University, tends to help them improve their quality-point standing. 


\section{Review of the Literature}

The first use of group psychotheray in tine United States was with adult patients with somatic disturbances. It was used as a didactic teahing metiod, and was known as "The Class Hethod." It was consioerably later that the method was used. with adult psyciniatric patients. The greatest strides in group therapy, however, have been made with children. Group interviews are most effective with adolescents and adults. Conversation is the same as in individual interviews. Group interviews yield clarification and release from enotional tension; break through anxieties; help the patient to gain insight into his problems; anả äevelop more wholesome attitudes towarả others.(19) Althougin the literature contains some writings about counseling and scholasticism, not very much has been done in the way of experimental research on the subject from a scientific viewpoint. There are a great many reasons for this, primarily because of the lack of agreentent among therapists and counselors, as well as others, as to a standardized definition of terms, and also because of the scarcity of reliable tools and measures with which to proceed.

In our attempt to find historical evidence supporting this study much of it has been as theoretical, or at least as inconclusive as this thesis must necessarily 
be. However, there are some students in the fiela who have been interested enough to consicier the same general problem as ours, or a similar one anyway.

Perhaps the most closely relatec experinent in this fielo has come right out of the University of Louisville itself. Godfrey, (10) in getting material for a thesis in the Department of Iducation in the University, made a study of veterans returning to college who were formerly probationary students. He refers to a statement by Heaton and Feedon (12) that mental ability is not the only important factor to be considered in the prediction of acadenic success or fallure. Many failing students have high scores on tests of mental ability. (I0)

Godfrey's study showed that of 75 students on probation, $28 \%$ of them had graduated in the upper third of their high school class. Of this 75, $82 \%$ lived at home and did not have to make adjustments on leaving home, as some college students must do. It is interesting to note that this group was amaiting call to Military Service anỏ had anxieties over it, as brought out in later interviews with the students.

A like number of $23 \%$ changed their major study. This Ied Gocfrey to state that "...factors other than ability, or lack of ability, to do coliege work...are interfering with the stucient... on probation." (10)

One instance in which a change of majors proved successful, although the change ras only incidental to an 
underlying problem, is illustrated by Gocirey in the case of $C$. who had been influenced by his uncle to study medicine. C. enrolled in a pre-medical course anci got on probation. He was called to service and served as a surgical techician. In so doing he realized ho dia not like the medical profession, and when he returned to school after his service, he deciced to take up law. Following this, an increase in his quality-point standing was noticed; although $\mathrm{C}$. credited the change of his major study as tire important ractor in his academic progress, (10) it is conceivable that the reason for choosing medicine in the besining may have had something to do with his lack of acjustment in college. In the case of J. (10) we have an instance of a boy who hac graduated in the lower third of his inigh school class. He joined the Neval program at the University and when he got on probation, he was sent out to sea cuty. After his return to school, he made excelient progress; he made 4 hours "A", 22 hours "B", and 8 hours "C".

In his Psycholozy class J. felt he had "been able to see through his problems and to take steps to correct them." (10) In spite of the fact thit he was in the class of high school graduates that might have been refused admission to the University (4) "J.'s scholastic success is exceptional... Naturity of purpose and accurate self-analysis must certainly have been the redeening factors." (10)

It certainly seews, from this stuày, thet there is a relationship between emotional adjustment and scholastic achievenent. One might hazard a guess that in the case of $\mathrm{J}$. 
his psychology class was one in the nature of group therapy. From the study prepared by Godfrey (10) it was shom that Forry over the War, lack or naturity, anc lack of interest were the most important factors mentioned in 24 interviews with the students regarding tineir progress. Attainnent of maturity and change of major, according to the students' own statements, were the most important factors aiding their progress.

There are several factors that influence achievewent, and it is not wise to lay too much stress upon any one of them. Wrishtstone (26) says: Mociern concepts in the evaluation of achievement require...not only acquisition of academic information and skills, but also interests, attituōes, appreciations, physical hoalth, and personal-social acaptability." Heaton and wecdon (12) in Chapter $X$ of their book mention the importance of personal and social factors $i$ achievement. The boy who is in love with a firl, for example; the student who wants friends; the student whose parents are experiencing marital difficulties; the student who loses a close relative through death; all these influences, they say, illustrate sone of the personal and social factors wilch may affect students' scholastic success.

An excellent example of this is given in thurphy and Lacid, "Enotional Factors in Learning," (17) a study of girls at Sarah Lawrence College in New York. In the chapter on The Role of "Problems" in Learning, they first state that "Approximately no more than one thira of a 
fresiman class has reached college age without ilaving to confront major family, social, or physical difficulties.... Irequently she (the normal coliege girl) brings her problems to coliege with her." (17, p.105)

Wurphy and Laci made an intensive case study of 25 girls at Sarah Larrence. It may be worthwhile to quote what they have to say as an indication of the proplems students may have. "...we found that 14 of the 25 girls haci experienced death of a parent, divorce of the parents, or extremely strained relatiuns between parents and children. Illustrations of the ways in wich early troubles can affect the student's acjustment at college are seen in Lucille, disturbed about a family scandal and always uncertain whether she vas as secure and as popular in the college group as she should be; Peggy, whose brother was described by her and anotiner student as a serious problem; Hazel, so worried about the hostile atmosphere between chilciren and parents in her home that her conferences were dominated by discussion of it. In another instance, Carol's inability to face reality ubjectively in relation to course material seemed to be a direct rerlection of her experience in family relationships; ana the same sumnary might be made of Beatrice. Harriette's hostility to teachers appeared to be a direct reflection of hostility towara domineering adults at home; Laura's insecurity was rooted partially in social aisorientation following the failure of her father in business; Sonia's scattered flights from one topic to another seemed to reflect a deep anxiety grown from $-12-$ 
the death of one parent and the lifelong illness of another. "Severe physical difficulties occurred in two instances. Great social strain occasioned by ambiguity of social status or collapse of family economic security existed in 3 cases, while anxiety over adoption, family sex problems, or the consequences of a temporary break in the family appeared in 3 adaitional cases." (17, pp.104-105)

Certainly it is plausible that such personal problems as tilese can prevent, the college student from doing his level best, even were we to doubt that they might not cause him to do his worst.

Two more studies that lend support to the relationship between adjustment and scholastic achievement have been publishea recently. Darley (6) gave the Bell Ad justment Inventory, the lininesota Survey of Social opinion, and the Minnesota Inventory of Social Attitude tests to 326 male and 217 female students at tre General College of the University of Minnesota in 1935 anc 1936. From the results obtained, Darley made the statement that mhile it is impossible to state from these data that... maladjustment...leads to student mortality....it does appear that...maladjustment... may depress achievement below the level to be expected from ability...."

Assum and Levy, (1) at tine University of Chicago, made a comparison of a group of adjusteci stuaients with a group of maladjusted stucients. Their achievement and aptitude were measured. 71 students at the University who were counseled during one year at the Counseling Center, 
were matched with a control group of 71 students at the University equated on the basis of sex, date of entrance into the college, and grade level of entrance into the college. The conclusion reached was that there was no difference in academic ability between the two groups, but there was a difference in achlevenent in favor of the adjusted group. (1)

In another experiment in which a control group was used in muci the same way, but with a greater number of stuaients over a longer period of time, similar results were obtained. Williamson and Bordin (24) studied the records of 405 Arts college freshmen at the University of ifininesota, over a perioa of four years. They were selected from the Counseling Bureau of the University on the basis of completeness of case data. The control groups were matched on the basis of college class, age, sex, size and type of high school, percentile rating, aptitude test score, and Cooperative English test.

In comenting upon their findings, Williamson and Bordin stated: "It may be contended that the fact that students in the experimental group voluntarily sought counseling... and that the control group did not, invalidated this matching procedure. If true, such criticism holds equally for the numerous learning experiments in psychology and education, and invalidates them, since it is usualiy stated in such experiments that it is assumed that motivation was conparable in the experimental and control groups." (24) It was also pointed out that the exact 
effects of self-selection are unknown, and may be either positive or negative.

The results showed the counseled group to achieve higher grades than the non-counseled group. (24) Toven (22) also made a study of students who had been counseled for four years, although he considered their grades for the first year only. His findings, on 188 students, were that the counseled students were more Iikely to graduate; had more point credits (quality points); and had a better recognition of their aims in attending college. Baller (2) became interested in the low scholastic records of some students. In a study of 46 freshnen who came for counseling for problems of emotional or social adjustment he demonstrated that practically all made poorer scholastic records than their rating or aptitude showed. "Evidently," he says, "scholastic dificulties resulted from or at least accompanied the problems which the...freshmen brought to the guidance counselor's office." Anna Fults, of the University of Arkansas, tried an experiment with a 7th and 8 th grade class in Home Iconomics (8) which resembles these other studies to some extent. She endeavored to determine why some students had more difficulty in learning than aid others. In order to discover some of the factors operatine in their difficulties, she gave them a series of psychological tests. Among the obstacles pointed out by the tests were: frustrated needs; conflicts in values; inadequate preparation; intense personal problems; overloaded life schedules; poor health; remoteness 
of goals; social structure; incapacity; and environmental blocks. Her experiment was one in human relations, in which the children were encouraged to take a genuine interest in the other members of the class; to help those that needed help; to be aware of the attitudes of their classmates; and to give support and security to those members of the class who were backward and withdramn. Miss Fults decided tirrough this experiment (8) that "...improving learning through...teacher education... which emphasized human relations within the total group, tended to result in significant increases in social acceptance, reading skills, and interest as measured by $a$ psychological test." It is more than likely that some of these devices will operate to some extent in our own study.

Borow (3) investigated some of the predictive methods of collegiate performance. Some of his results showed that many tests of intelligence, such as hign school record exams, and content exams, give a Median correlation with collegiate performance of only .45 which is only about $11 \%$ better than guesswork. The best combination of intelligence tests, content exams, and high school record exams rarely gets a correlation over .75. This is still less than $34 \%$ better than guesswork, according to Borow. In spite of all these tests, he remarks, we are "forced to the conclusion that the greater part of the difference among college students in academic achievement is still unaccounted for by the prognostic instruments in current use." 
An important factor in the "academic achievement of any student is the result of combined influences of a great many behavioral influences." The typical college aptitude test shows how much intellectual promise the student has, says Borow, but does not show to what degree the student will use his promise. "... it is more than conceivable that the achievement of a college student is in part shaped by such personal anả non-intellectual considerations as tinese: Does he adjust well to the inevitable regimentation and routine of academic life? Is his desire for a college education founded upon mature and sturdy motives? Is he worried about financing his academic career? Is he carrying too arduous a load? Does he proportion his time wisely amont tile many activities in which he engages? Is he in good health? Is he beset by irrational feelings of failure and insecurity?"

A similar conclusion was reached by winston in his studies of freshmen at North Carolina State in the late 30's. (25) In his investigation he considered only three factors: economic insecurity, delayed matriculation, and uncertainty of vocation. He observed that four-fifths of thefreshmen earned part or all of their expenses; almost half of them earned 50\% of their expenses. Only about two-thirds of the fresimen had come to college directly from high school; almost one-fifth were out a year before entrance, andone-seventh were out from 2 to 9 years. As to the choice of volation, $36 \%$ were uncertain, and $25 \%$ had no choice at all. This gave rise to the conclusion that social 
and personal factors may be as important in adjustment as purely scholastic achievenent or intellectual ability. (25)

Wagoner (23) reported in ail Abstract some results he found in relating achievement and adjustment. He took from 35 to 64 patients while they were in a state of anxiety and administered Kohs Block Test to them. Hie re-tested them after an interval when the anxiety hac subsided. The results inaicated that "ranxiety exerts a detrimental effect upon most subjects, on the level of performance on these tests." (23)

Hriting in a pamphlet publishec by the University of Missouri Press, Garnett makes the statement that "...the failures resulting from the lack of ad justment are unquestionably reflected in unknown and untold loss of time and woney, in discouragement, in depression and human misery, in increased difficulty in adjustment to other lines of work, and in distorted views of life....there is a definite need...for a method of guiding the student into those courses and toward those occupations for wich his abilities and inclinations make him well adapted."

Ferguson and Crooks (7) made one of the few studies concerned with Quality Point Ratios. They took the four-year records of 341 students graduated from the University of Conecticut in 1937 through 1939 and investigated the relationship of the Q.P.R. and ability. They arrived at three possible conclusions: 1. the proportion of better than average Q.P.R.'s automatically increases in upper division years, anci the proportion of lower than 
average Q.P.R.'s automatically decreases in proportion to what they were in lower division years. 2. Q.P.R.'s of adjacent semesters tend to correlate higher with each other than those further removed. 3. "The tendency for the correlation between scholastic aptitude test scores and grades to become lower with each successive semester indicates that the kind of ability measurea by the test... becomes less important....This would again point to the desirability of developing ather...predictive instruments which would...measure the factors contributing to success and failure...." (7)

In another correlation experiment, somewhat related to the problem, Montalto attempted to correlate college acifievement and intellectual ability by mean of the Group Rorschach technique. (15) He did his study on 90 women students at the University of Cincinnati, using grade-point averages (quality-points) as a measure of achlevement, and the A.C.E. test as a measure of intelligence. He made correlations and partial correlations, and produced two somewhat contradictory observations: 1. achievers showed more signs of good adjustment than did nonachievers; 2. achievers had a neurotic treno in their personality which may be an important factor in their achievement. (15) This second observation may be very significant as an argument that achievement is not always a sign of integration.

The use of the Rorschach by Muench (16) to evaluate non-directive therapy indicates that some of the $-19-$ 
effects of therapy might be important factors in any improvement in achievement. In adcition to the Rorschach Wuench used the Bell Ad justment, both without a control group, and proffered the conclusion that therapy "tends to develop more integrated personal control, a ricier and more mature inier life, more accurate perceptions, greater emotional adaptability and control, a greater social adaptability, and a decrease in anxiety. The greatest changes which occurred...are,as follows: a decrease in anxiety; a greater degree of personal integration; a greater tendency toward doing the expected thing; and a better integrated emotional life, incluaing greater emotional stability, control, and adaptability." (16)

If, as we have been shown, anxiety, lack of enotional stability, lack of maturity anả social aảaptability, and so forth, are problems affecting scholastic acilieverient, then we may hope that alleviating these conditions (timough therapy) will have a consequential effect on collegiate performance.

In an endeavor to verify or nullify Muench's experiment (16) Hamlin and Albee (11) at Pittsburgh were able to provide a control group of subjects comparable in age, sex, education, and adjustrent problems with those of Muench's group. They found no significant changes in their no-therapy control group on the Rorschach scale, and concluded that "it has been demonstrated that significant changes in personality structure accompany the experience of non-directive therapy, and are not associated with the 
passage of time." (II). It might be assumed that such cianges wight occur through group therapy, also. And thus we have some evidence that there is a relationship between scholastic achievement and adjustment in college students. We have seen that problems of adjustment have afiected graces, and that when these problems were dealt with that an improvement in grades was noticeable. We have also been shown that counseling, in various forms, has been of some value in dealing with these problems, ana we may assume that it has been a factor in improvement in achievement in this way.

Iuchins (14) declares that persons who acknowledged value from group therapy took positive action as a result of it; carried over their changes in attitudes and actions into other fielos; and felt that they were changed personally rather than having their specific problems solved. This has been borne out by the difierent authors we have reported above.

Now we come to the method by which our experinent will be handled. It is necessary to conduct it on a group basis, rather than an indiviciual basis, on account of the large number of students to be counseled, and the small size of the Center staff. However, Sternbach (20) says that "Unequivocally: Group therapy is a therapy in its own right, and on the same level as individual therapy, but one which probably has even wider applicability."

Some suggestions for a therapy group are oflered by Hulse. (13) He says that patients should not be selected 
too closely; the therapist should be trained; the sessions should be regular and continuous, and the number in the groups should be small, under 20 if possible. Our groups will resemble this description to a great extent. Again referring to sternbach (20) he advises that "the interest a patient may take in a specific group will not necessarily be identical with the announced group purpose. Neither will the patient always be conscious of the character of his interest...the interest tne members take in the group need not be the same for all members... The avowed pur wose of joining can even be a mere excuse for joining..." If this be true, it may fit our case very well.

In the matter of controls for our experiment, (we have showed cases where controls were used and where they were not) we have to try to overcome the difficulties involved in setting up a control group. Some writers have taken the stand that control groups hay be impossible to organize. Rogers (18) says in getting groups for controls it is hard to "match clients comparably as to the seriousness of their problems...." He susgests a control between the earlier and later interviews of the same client. "Perhaps we cannot set up control groups in the usual sense." (18) In the same article (18) Brennan remarks that "...the stuajy of problems of internal consistency is...more fruitful than the establishment of control groups."

In the same vein, Burchard, Michaels, and Kothov declare that "Sat1sfactory controls in individual therapy 
are aifficult to establish; in group therapy, in which so many nore variables are present, the difficulty becones multiplied... few if any of the publisined reports on group psychotherapy have dealt with the problem of control." (5) In closing our review of the literature, we might quote from a review of the literature, written by Thomas (21) in 1843. "It is apparent that powerful forces can be mobilized in groups which are capable of producing remarkable results in the individual making up the group... there is ample eviäence in the recent literature of the effectiveness of group psychotherapy in all psychiatric conaitions." If that were true in $1 \subseteq \$ 3$, it shoula be so much more true in 1949 . 
III. Statement of the Problem, Metiods and Procedures

Students in the College of Arts and Sciences are graded on a five-level basis; these grades range from "A" through "F" and the quality points earned per semester or quarter hour depend upon these grades. "A" is Excellent and gives 3 quality points for each semester or quarter hour; "B" is Good or Superior and gives 2 points per hour; "C" means Average, andgives I point per hour; "D" is Passing but Poor and carries 0 points per hour; while "F" means Falling and has minus one (-1) points, or in other woras, subtracts one quality point for each hour "F". (4) It may be feasible from the standpoint of statistical analysis to consider "F" as giving credit hours, in order to make a continuous scale of quality-polnts. This would keep the variable of hours constant.

The standard for acceptable scholarship in the College is an average grade of "C" or a quality-point stanoing of 1.0. This average is generally known as the Q.P.R., or quality Point Rat1o. When a student's total quality-point stancing goes down six points or more, 1.e., when he has six or more total quality points less than total semester or quarter hours, he is placed on probation. Students on probation who make a 1.0 or better stanciigs for one semester may be continued on probation until their total stanaing is 1.0. (4) 
Stucients admitted to the Freshman class in the College must usually meet the following requirenents for admission: they must have graduated from a four-year accredited high school; they must have passed a General Scholastic Aptitude Test, and an English Usage Test; and if the student's average on these tests is below the 26th Percentile, and he also ranked in the lowest third in his high school class, he may be refused admission to the College, or else he may be admitted on probation. (10) The problen, then, is whether group counseling of these probationary students can be helpful to them in getting off probation by increasing their quality-point stancins. Actually, getting of probation itself is not a strict goal, or criterion of this experiment, for it is set up on the basis of the semester quality-point standing, rather than the aggregate point standing. As has been stated (4) an increase in one semester's quality-point standing will not release the student from probation if his overall standing is less than 1.0 .

We are interested, not only in finding out if group counseling will be effective as stated above, but also in some of the factors that may be involvec among those students who receive counseling. Ve should like to know, for Instance, if all students on probation at any time can be counseled as a matter of course, or whether involuntary counseling can be given as well as voluntary counseling. While we do not expect a conclusive answer to 
these questions, we hope to provide some opportunities for further research and investigation in this realm.

The group counseling :ill be provided by means of a non-credit course ofiered by the Psychological Services Center for the probationary students. It may be called an orientation course, or given any otiner approprlate title. All students on probation in the College during one semester will used as the population, from which samples will be selected. Quality-point stancings of the students for the semester preceding counseling, and for the semester following counseling, will be used as criteria.

The students will first be separated into tiree divisions, and an Experimental Group and a Control Group will be chosen from each of these divisions. First, one tiird of the students wili be selected at random from all tilose on probation. It will be assumed that this group will include a proportionate number oi students who want counseling and who do not. This group may be called Group $R$, and will give us a sauple of the population at large to be neasured; it will also be an index of ruture sthicuts on probation.

The reraining two thirds of the students will be divided according to their desire or undesire for counseling. The orientation course wili be suggested to these stuaients by the College, and those who corre over to the Center to enroll in it vill be consicered those who ciesire counseling. Those who do not come over will be 
considered those who dio not have a desire for counseling. The former group nay be cilled Group w; the latter group may be calleà Group $D$.

A. random sample of each of these groups, $R$, $W$, and $D$, will be selectea, diviaing each group in half. This will give us, then, two sub-groups in each group, or a total of six groups at this point. Three sub-groups from $\mathrm{R}, \mathrm{W}$, and $\mathrm{D}$, will comprise the Experimental Group, $\mathrm{X}$, which is to have counseling; the remaining three sub-groups from $\mathrm{R}$, W, and D, will comprise the Control Group, $\mathrm{Y}$, which is not to have counseling. In this way, Group $X$ and Group $Y$ will each contain students who want counseling, students who do not, and students who did not express a choice.

The Experimental Group $\mathrm{X}$ will include $\mathrm{X}_{r}, \mathrm{X}_{\mathrm{F}}$, and $X d$; the Control Group $Y$ will Include $Y r, Y w$, and $Y d$. Group Xd will be required by the College to take the orientation course, in a manner to be agreed upon by the college and the Center. Group Yw will be placed on a "waiting list" for the orientation course. This is not too desirable a circumstance, but it is necessary so that the situation can be handled without creating a systematic bias.

Group $X$ will be divided into smaller size groups, by ranciom selection, to facilitate counseling; the number of groups depencing upon the total $N$ of Group $X$. Counseling in these groups will be by Staff menbers of the Center assigned to each group, with the method of counseling to be left to the discretion of each counselor. The sampling in 
all instances in this experinent will be from the Table of Ranciom Numbers.

It will be possible, by this division of groups, to compare students selected from the general population with those who wanted counseling and those who did not. The results may be analyzed or correlated by aifferent methods and for different purposes, by anyone who may be interested in some other phase of the experiment. If the increases in Q.P.R. are significant, as far as this experiment is concernod, it may enable the College to determine whether or not choice in the matter is an important factor.

The measure of the efiectiveness of the experiment will be obtained by the increase or decrease in quality-point stancings of all the probationary students for the semester following the group counseling, over the semester preceding the course. The criteria will be analyzed and examined by making a Critical Ratio of the differences between the lieans of each group. The $\mathrm{CR}$ is one of several statistically valid measures of testing significance, and is being used arbitrarily. It will indicate whether any increase in quality-point standing is significant, or merely due to chance. 


\section{Comments}

We have tried to eliminate as many undesirable factors from this stuay as possible, and also to consider every angle of the problem. In so doing, we hoped to be able to present results which would be true and consistent as far as the experiment goes. It is obvious that in any study of this nature there will be so many variables that cannot be excluded or overlooked, so many factors in operation that cannot be controlled or rulea out, so many hypotheses that are bound to spring up, that it would necessitate not only nany different kinds of research to obtain any reliable conclusions, but also more investigations of the same situation.

For instance, if signiricant increases in quality-point standings are shown as a sequence of group counseling, how we can account for all the otier environmental influences tinat may be operating, how we might find out what they are, how we would measure them if we did, all these questions must remain unanswered. If one of the groups shows an increase in Q.P.R. anc anotiner group does not are we to attribute it to the particular therapist, or to the particular group, or to any specific individual or condition in the group?

Suppose a decrease in Q.P.R. is evicient; are we 
going to assume that it is the result of the group counseling course? How will we "explain" it? Suppose their are no students who want counseling; or trat do not? There are many questions that can not be answered with satisfaction; some can be answerea only after scrutinizing the results at hand. Lut we must be aware of the possibility of these things, and not become so imbued with our own postulates that we will not ourselves "face reality objectively," to coin a phrase.

However, our study does have merit in that if negative results are shom, it will not necess rily nullify the experiment. Such results would provide us with a means of examining our whole undertaking so that we might correct some of the errors anci false assumptions we had made previously.

In the statistical analysis of our findings we have not been interested in any correlations between groups or between items. We have only been interested, for the sake of this experiment, in the one criterion of an increase in Q.P.R. The results will be presented so that anyone desiring any correlations may make them with little difficulty.

In conclusion, we realize only too well that we hiave probably left much undone, but we feel that even in this initial undertaking we have gained insigint into our own failures, and have profitted by this experience. If this study has given us the appreciation of the subject, the value of research in the field, as well as of research $-30-$ 
methoas, then we feel tinat the time and effort put forth have been well worth the while.

Perhaps it will not be impertinent at this

point to express appreciation to the Director of this

thesis and to all those in the Department who were kind enough to submit benefits of their knowledge and experience to our efforts. 


\section{Summary}

An exploratory study of the affect of group counseling on probationary students has been proposed. The Psychological Services Center of the University uf Louisville is now offering counseling services to the College of Arts and Sciences of the University for the benefit of the students on probation in the College. It is in the hope of finding some measure of the elfectiveness of these services that this experiment was set up.

We have observed in a similar study that former veteran probation students experienced problems of adjustment in connection with their scholastic difficulties. We have learned through other studies that acquiring information is not the only factor involved in measuring achievement, but that personal-social factors also play an important part. We have presented brief case studies of the personal problems affecting students in a girls school. Wuch of this information has been gained through interview techniques.

Some experimental studies have also been tried In which evidence has appeared that there is a definite relationship between adjustment and scholastic achievement. In one such experiment it was demonstrated that adjustment problems were responsible for some students to fall below their scholastic aptitude. Psychological tests 
have been given to indicate some of the emotional problems confronting college students. Studies of the success and of the failure of students have been made. There have even been studies of the predictive methods used for scholastic performance.

There seems to be an abundance of evidence to support the relationship between problems of adjustment, personal, social, ano emotional, and performance or achievement. This relationship, of course, is not confined to college students, or to any other students for that matter.

In the literature we have also read of the studies that have been made to evaluate counseling and therapy, and to indicate some of the results that may be realized from therapy, including group therapy. Some of the studies have been experimental in nature, with the application of a control group, while others have not established controls, and still other have been chiefly theoretical in content.

The results from all of these reports tend to credit therapy with the means of dealing with these problems of adjustment in an effective manner. Findings that show what is accomplished in therapy itself, as well as studies that reveal results that accompany or follow adjustment in "successful" therapy, may be referred to in substantiation of this.

Tus, we can by deduction, if not through induction, conclude that: 1 . college students have problems of adjustment that affect their achievement in school; 2 . counseling $-33-$ 
and psychotherapy are effective means of treating problems of adjustment; 3 . an improvement in the person himself through help with his problems is carried over into other areas of his personality and environment; and, 4. therefore, an improvement in performance in college students may be ensuing. 


\section{Bibliography}

1. ASSUH, A.I., \&E INVY, S.J., A comparative study of the academic ability and achievenent of two groups of college students. J. educ. Psychol., 1947, 38, 307-310.

2. BALLER, w.R., Characteristics of college students wino demonstrate interest in courseing services. J. educ. Psychol., 1944, 35, 302-308.

3. BOROW, H., Current problems in prediction of coliegiate performance. J. Amer. Ass. coll. Registr., 1946, $20,14-26$.

4. BULLETIN, University of Louisville, 1948, 1, 54-55.

5. BURCHARD, BDE.....L., HICHAELS, J.J., \& KOTHOV, B., Criteria for evaluating group therapy. Psychosom. Hed., 1048, 10, $257-271$.

6. DAPLEY, J.G., Scholastic achievement and measured maladjustment. J. appl. Psychol., 1937, 2I, 485-493.

7. FERGUSON, L.W., \& CROOKS, W.R., Some characteristics of the quality Point Ratio. J. genil. Psychol., 1942, 27, 111-113.

8. FULTS, A.C., Improving learning through an exphasis on humen relations. Child. Educ., 1948, 24, 305-307.

9. GARIETI, R.I., Some factors in college success. Columbia, Iiro., U. Of Missouri Press, 1934. $65 \mathrm{pp}$. 
10. GODFREY, R.E., A study of the academic success of veteran former probation students in the Collese of Arts and Sciences of the University of Louisville. Unpublished Raster's thesis, U. of Louisville. 1947. $88 \mathrm{pp}$.

11. HAILIN, R.M., \& AIBEE, G.W., Juluench's tests: a control group. J. consult. Psychol., 1948, 6, 412-416.

12. HEATON, K.L., \& WEDON, V., The failing student. New York. Columbia U. Press, 1939. 279 pp.

13. HULSE, W.C., Report on various experiences in group psychotherapy. Jewish soc. Serv. Quart., 1948, 25, 214-220.

14. IUCHINS, A.S., Methods of studying a group therapy program. J. consult. Psychol., 1947, 4, 173-183.

15. MONTALTO, F.D., An application of the Group Rorschach technique to the problem of achievement in college. J. clin. Psycinol., 1946, 3, 245-260.

16. MUENCH, G.W., An evaluation of non-directive psychotherapy. Appl. Psychol. Hono., 1947, 13, $163 \mathrm{pp}$.

17. HURPHY, L.B., \& IADD, H., Emotional factors in learning. New York, Columbia U. Press. 1944. 404 pp.

18. ROGERS, C.R., Research in psychotherapy: round table. (Brennan, Margaret) Amer. J. Orthopsychiat., 1948, 18, 112-118.

19. SLAVSON, S.R., Group therapy in child care and child guidance. Jewish soc. Serv. Quart., 1043, 25, 203-215. 
20. STERBAACH, 0., Techniques in group therapy. Jewisin soc. serv. quart., 1948, 25, 221-224.

21. THOMAS, G.W., A review of recent literature. Psychosom. Med., 1943, 2, 166-180.

22. TOVEN, J.R., Appraising a counseling program at the college level. Occupations, 1945, 23, 459-466.

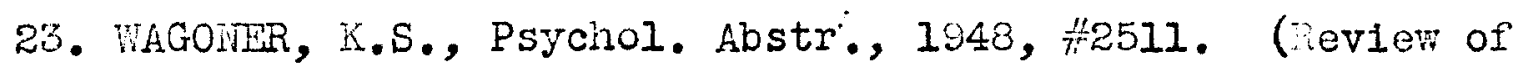
Abstract by Diethelm, O., B Jones, M.R., Arch. Neurol. Psychiat., Chicago, 1947, 53, 325-336.)

24. WILIIAHSON, E.G., \& BORDIN, I.S., Evaluating counseling by means of a control-group experiment. Sch. \& Soc., 1940, $52,434-440$. .

25. VINSTON, $F$., Selected factors affecting student adjustment. J. educ. Sociol., 1540, 13, 546-551.

26. WRIGITSTONE, J. W., Evaluating achievenent. Childh. Bauc., $1948,24,253-259$. 